\title{
Pulmonary rehabilitation in multi-drug resistant tuberculosis (TB MDR): a case report
}

\author{
Esther Cecilia Wilches, PT ${ }^{1}$, Julián Andrés Rivera, PT² ${ }^{2}$ Ricardo Mosquera, MD³ \\ Liliana Loaiza, TO ${ }^{4}$, Lucely Obando, Psicol ${ }^{5}$
}

\section{SUMMARY}

Introduction: In tuberculosis $(\mathrm{Tb})$, the great inflammatory component causes major injuries that trigger fibroblastic reaction, fibrosis and chest wall retraction, compromising pulmonary expansion, which translates into a clinically and functionally moderate restrictive pattern and dyspnea during exercise. This favors lung disability, causing economic and social dependence upon the nuclear family. Measures to control the $\mathrm{Tb}$ disease are merely focused on healing; and this fact must be considered insufficient because the actions aimed to habilitation and rehabilitation could prevent or reduce the incidence of Tb by cardiopulmonary disability. The importance of pulmonary rehabilitation (PR) as a nonpharmacological treatment in patients with chronic respiratory disease and/or risk factors for acquiring such is documented in the literature, and its application improves the physical condition of the patient and restores health-related quality of life (HRQOL), autonomy, and social integration.

Objective: To describe the deterioration of the functionality of a patient with multi-drug resistant tuberculosis (MDR-TB) and that patient's recovery in a PR program.

Results: An increase of the distance covered in the six-minute walk test (6MWT) from $240 \mathrm{~m}$ to $350 \mathrm{~m}$ was observed. Dyspnea score with the medical research council (MRC) improved from 4 to 1 , and improved from 7 to 0 with the Borg scale. The upper and lower limb muscle strength increased from 3 to 4 .

Conclusion: A period of PR of 8 to 10 weeks was enough to improve patient functionality.

Keywords: Pulmonary rehabilitation; Multi-drug resistant tuberculosis; Functionality.

Rehabilitación pulmonar en tuberculosis multirresistente (TB-MDR): Informe de un caso

\section{RESUMEN}

Introducción: En la tuberculosis (TB) el gran componente inflamatorio, ocasiona lesiones importantes que desencadenan reacción fibroblástica, fibrosis y retracción de la pared costal, y comprometen la expansión pulmonar lo que se traduce clínica $\mathrm{y}$ funcionalmente en un patrón restrictivo moderado y disnea al ejercicio. Lo anterior favorece la discapacidad pulmonar, y ocasiona dependencia económica y social del núcleo familiar. Las medidas tendientes a controlar la enfermedad tuberculosa son sólo curativas, hecho que se debe considerar como insuficiente porque las acciones dirigidas hacia la habilitación y rehabilitación podrían evitar o disminuir la incidencia de discapacidad cardiopulmonar por TB. La importancia de la rehabilitación pulmonar (RP) como tratamiento no farmacológico en pacientes con enfermedades respiratorias crónicas y/o con factores de riesgo para adquirirlas, está documentada en la literatura, y su aplicación permite mejorar la condición física del paciente, restaurar la calidad de vida relacionada con la salud (CVRS), la autonomía y la integración social.

Objetivo: Describir el deterioro de la funcionalidad de un paciente con tuberculosis multirresistente (TB-MDR) y su proceso de recuperación en un programa de RP.

1. Assistant Professor, Physiotherapy Program, Director of the Exercise and Cardiopulmonary Health Resarch Group, School of Medicine, Faculty of Medicine, Universidad del Valle, Cali, Colombia. e-mail: esterwil@univalle.edu.co

2. Physiotherapist for the Pulmonary Rehabilitation Program, Hospital Universitario del Valle, Cali, Colombia. e-mail:juliancho2112@hotmail.com

3. Pulmonologist, Internal Medicine Unit, Hospital Universitario del Valle, Cali, Colombia. e-mail: rpmosquera@hotmail.com

4. Physical Medicine and Rehabilitation Unit, Hospital Universitario del Valle, Cali, Colombia. e-mail: lilo69gallardo@yahoo.com.ar

5. Psychologist, Burn-victims Unit, Hospital Universitario del Valle, Cali, Colombia. e-mail: lucelyo@gmail.com Received for publication June 3, 2008 Accepted for publication September 30, 2009 
Resultados: Se observó un aumento en la distancia recorrida en el test de caminata de los seis minutos (TC6M) de 240 ma $350 \mathrm{~m}$. La puntuación de disnea con la escala del Medical Research Council (MRC) mejoró de 4 a 1 y con la escala de Borg mejoró de 7 a 0 . La fuerza en la musculatura de los miembros superiores e inferiores aumentó de 3 a 4 .

Conclusión: Para este paciente un periodo de RP entre 8 y 10 semanas de duración, fue suficiente para mejorar la funcionalidad.

Palabras clave: Rehabilitación pulmonar; Tuberculosis multirresistente; Funcionalidad.

Multi-drug resistance to antituberculous medicine (defined as the resistance, at least, to isoniazide and rifampicine) is widely accepted as a threat against the control of tuberculosis ( $\mathrm{Tb}$ ) in various parts of the world.

In Colombia, according to the WHO/OPS (2004), the estimated percentage of multi-drug resistant $\mathrm{Tb}$ in patients without previous treatment was around $1 \%$ to $3 \%$; however, there is not sufficient data reported on the estimated percentage of multi-drug resistant Tb in patients with previously treated $\mathrm{Tb}^{1}$. By 2005 , nearly 10,000 cases of $\mathrm{Tb}$ were diagnosed, and approximately $15 \%$ of these were detected in Valle del Cauca (Guía Nacional de TB, 2005).

When confronting diseases that are yet to be prevented, far less cured, pulmonary rehabilitation arises as the best possibility focused on diminishing the impact of the disease on the lives of those who endure it, and also on diminishing its social and economic consequences. Scientific evidence on the benefits of pulmonary rehabilitation programs is solid, and it has been proven in every patient with chronic respiratory illness and dyspnea, aside from the state of severity of the illness; hospitalwise, outpatient, and at homecare level. Patients with chronic respiratory deterioration show increased respiratory effort, muscular alteration, depression, and nutritional changes that form a cycle of inactivity and major physiological deterioration that may even occur during rest. This cycle must be stopped with an adequate integral general treatment in a pulmonary rehabilitation program that contemplates at least 6 weeks of physical exercise (evidence type B), mandatory aerobic physical training, walking or ergo cycling (evidence type A), education for the patient and the family (evidence type 1B), psychosocial intervention (evidence type 2B), and nutrition (evidence type $2 \mathrm{C})^{2}$.
This report describes the deterioration of the functionality of a patient with multi-drug resistant $\mathrm{Tb}$ (MDR-TB) even to the point of such patient losing the ability to perform every-day activities, as well as his progress in a pulmonary rehabilitation program, taking into consideration the scarcity of reports on the subject in Cali.

\section{CASE REPORT}

The components used in a pulmonary rehabilitation program for patients with MDR-TB are described in this report, adhering to the framework of the "Guia de Práctica Clínica de Fisioterapia» published by the American Association of Physical Therapy (examination, evaluation, diagnosis, intervention, re-evaluation). Also described are the conceptual definitions upon which the model of the International Classification of Functionality and Disability (CIF) are based: deficiency, limitation of activity, and restriction in participation (CIF): 26-yearold patient, male, Afro-Colombian, high school graduate, from Buenaventura (Colombia), a port city on the Colombian Pacific Coast with a high incidence of $\mathrm{Tb}$, where $48 \%$ of the population does not have coverage of basic needs; the rate of unemployment is estimated at $60 \%$, and health coverage is under $40 \%{ }^{1}$. The patient has no history of smoking, sedentary lifestyle, and/or exposure to toxic substances, basic primary-secondary educational level, and low socioeconomic level.

The patient was diagnosed with pulmonary $\mathrm{Tb}$ in 1997 and had a history of multiple complete treatments. He was initially treated with isoniazide, rifampicine, pirzinamide and etambutol, medicine that was suspended to receive treatment at home based on herbs recommended by a healer from the community. The patient's condition between December 2004 and 2006 is unknown, until he was admitted to Hospital Universitario del Valle, Cali, in July 2006 with respiratory insufficiency.

He was admitted to the Pulmonary Rehabilitation ProgramatHospital Universitario del Valle (in December 2007), and was wheel-chair bound and assisted by his care-taker, dependent 10/100\% when accomplishing daily life activities (DLA), and totally dependent on activities with instruments.

In the initial physiotherapeutic evaluation, deficiencies were identified in the patient's aerobic capacity, 
ventilation and gas exchange, joint mobility, and muscular performance.This patientrevealed reduced pulmonary sounds with roncus, rails and diffused wheezes; he depended on oxygen with a nasal cannula at $4 \mathrm{l} / \mathrm{m}$ nonstop, could barely speak, displayed fast breathing pattern, shallow breaths predominantly in the superior rib area, with dyspnea during short effort, thorax expansion reduced in lower lobes; effective cough with mucous secretions in moderate quantity, with generalized loss of muscular strength in upper and lower limbs according to the Daniels Scale (3/5). In the test for pulmonary function, the flow-volume curve showed severe mixed compromise(VEF1 15\%, CVF 31\%, VEF1/CVF 40\%) without response to inhaled bronchodilator; the arterial gases showed hypoxemia. The chest CT scan showed a pattern of ground-glass appearance in the pulmonary apexes, emphysematous bullae, cavitations on right apex and bilateral bronchiectasia.

In the 6-Minute Walk Test (6MWT) done in a 30meter long hallway, the following data was registered: partial oxygen sats $\left(\mathrm{SpO}_{2}\right)$ and heart rate $(\mathrm{HR})$ during the whole test, monitored through wireless telemetry. The degrees of dyspnea and fatigue were evaluated at the beginning and at the end of the test, using Borg's modified scale. The laps and meters accomplished were registered at the end. Two tests were performed in the morning, and the one with the greatest distance in meters was registered. Oxygen flow was adjusted to keep $\mathrm{SpO}_{2}$ at/over $90 \%$. At the beginning and end of the rehabilitation, the chronic dyspnea during the DLA was quantified with the MRC scale.

The patient evidenced deterioration in his quality of life, due to the increase of respiratory symptoms that limited his capacity to accomplish daily-life activities such as working, studying, visiting family and friends, which restricted his participation in social activities.

During the initial performance evaluation in the area of DLA (self-care, hygiene, dressing, and feeding), the patient accomplished a participation of $10 / 100 \%$. In activities involving instruments (preparing meals, housekeeping, and caring for others) the patient was totally dependent on his care-taker. He was not involved in any productive or leisure-time activities. About his emotional state, the initial evaluation through a clinical interview revealed that the patient was conscious, oriented in the 3 spheres: time, person, and place with a self-perception of uselessness, thoughts of handicap, low tolerance to frustration and acknowledgement of the direct responsibility that he had over his current physical state. The Hospital Anxiety and Depression Scale (HAD) was applied with a score of 2 on the depression component and 7 on the anxiety component, related to fear caused by his health problem.

In this particular case, there were administrative difficulties to finish a complete nutritional evaluation, and the patient only received some dietary recommendations.

The educational component in this patient was not totally evaluated or developed; nonetheless, the educational content was adapted to his social and cultural situation during the training sessions. He was given information on the disease and consultancy in the use of inhalers and methods to improve dyspnea, as well as tips for the treatment and prevention of exacerbations.

The quality of life was evaluated at the beginning and at the end of the training program through the SF-36 v.2 Health Questionnaire, which ranges from 0 to 100 , and where the highest points indicate a higher quality of life. Permission to use the questionnaire was obtained from the Unit of Research in Sanitary Services (IMIM) in Spain.

After the initial evaluation conducted by the whole interdisciplinary team, an intervention program was established, using strength and resistance training for upper and lower limbs, education, and techniques of energy conservation. In this case, the physical training was performed on a stationary bicycle, a treadmill and a step trainer, initially using a load equivalent to $30 \%$ of the maximum load, which was increased progressively until reaching a pre-established maximum load of $85 \%$, or the maximum load the patient would be able to carry for 60 minutes. All training sessions were supervised by a physiotherapist specialized in pulmonary and cardiac rehabilitation. The patient worked on strength and resistance training of upper and lower limbs. During the exercises, oxygen flow was adjusted to keep $\mathrm{SpO} 2$ above $89 \%$, and the patient had bronchodilator medicine prior to the start of physical activity. He attended rehabilitation sessions 3 times per week for 1 hour, for a period of 32 weeks, for 4 months (there were inconvenient situations regarding authorizations for rehabilitation, economic problems and transportation problems). During the training sessions the patient was collaborative, had expectations, was motivated, 


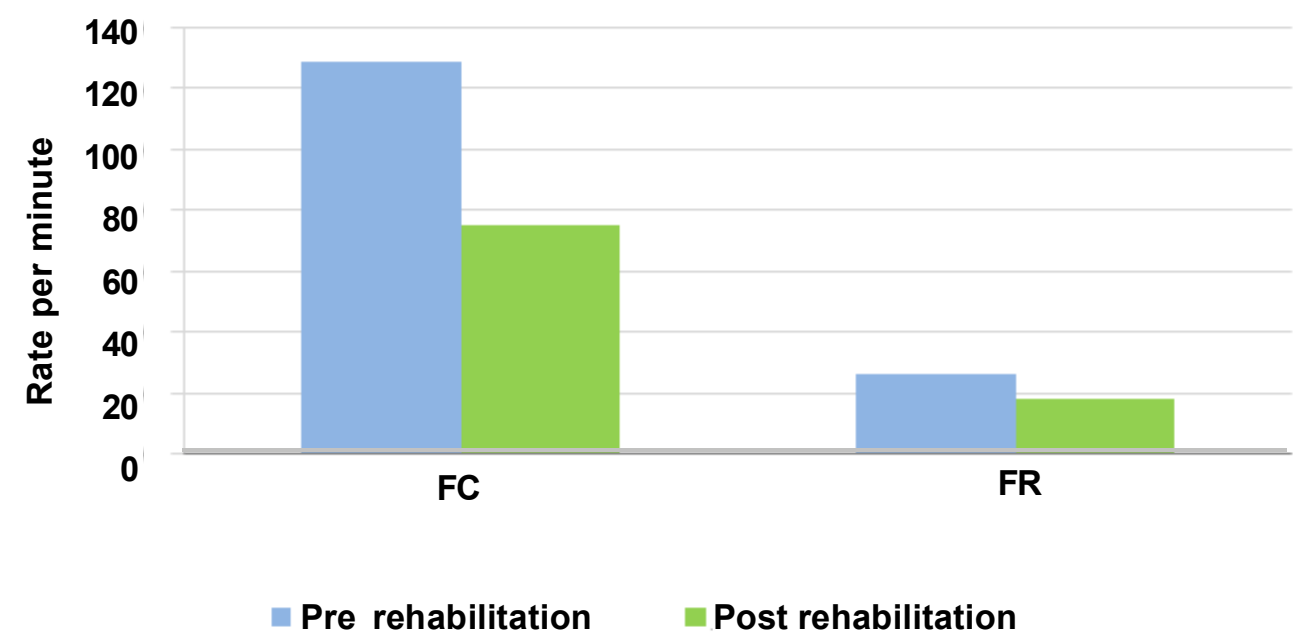

Graphic 1. Pre and post rehabilitation

HR: Heart rate; RR: Respiratory rate. Blue: the scores reached pre-rehabilitation. Green: the scores reached post-rehabilitation. July $24^{\text {th }}, 2007$. Pulmonary Rehabilitation Program

participated in the educational and recreational activities, and his family was permanently present.

The patient signed consent for the Rehabilitation Program, and authorized publication of this material.

\section{DISCUSSION}

Therapeutic failure in $\mathrm{Tb}$ has repercussions both in the workplace and in the social environment, because of the economic loss attributed to the absenteeism and inability to work. It also becomes a public-health problem because the patient continues being a center of infection in the community and can lead to the dissemination of resistant forms. The risk factors for the development of resistance include inhabiting endemic zones of $\mathrm{Tb}$ with high resistance, close and prolonged contact with people infected with resistant $\mathrm{Tb}$, and previous therapy that did not cure the disease. The residual damages on the pulmonary tissue after concluding antimicrobial therapy can include different degrees of fibrosis, bronco-vascular distortion, emphysema, bronchiectasia, and increased production of sputum ${ }^{3}$.

Chronic pulmonary patients, although receiving all the pharmacological efforts available, generally continue having physical limitations when it comes to effort. In $\mathrm{Tb}$, the great inflammatory component causes serious injuries that trigger fibroblastic reaction, fibrosis and chest wall retraction, affecting mobility, which compromises pulmonary expansion. The diaphragm can be functionally affected; the pleurodiaphragmatic adherence retracts it and shortens it, affecting normal movement. These mechanical problems affect the ventilatory function at costal and diaphragmatic level. This favors pulmonary disability, causing economic and social dependence upon the nuclear family. The measures that tend to control the disease are merely meant to heal, and this must not be considered sufficient because habilitation and rehabilitation actions could avoid or diminish the incidence of cardiopulmonary disability due to $\mathrm{Tb}$. The patients that have completed antituberculous treatment evolve with a pulmonary disability due to cavity disease.

Some studies show the benefits of pulmonary rehabilitation in patients with a history of Tb. Ando et $a l .{ }^{4}$ compared the effects of a 9-week intervention rehabilitation program in patients with chronic obstructive pulmonary disease (COPD) and patients with after effects of tuberculosis, and found no significant changes in the VEF1 after rehabilitation in both groups. They did find evidence of improvement in the dyspnea measured with the MRC in daily-life activities and in the distance covered in the walk test: $42 \mathrm{~m}$ in patients with Tb and 47 $\mathrm{m}$ in patients with COPD $(\mathrm{p}<0.01)^{4}$. These data coincide with this report in which the distance covered in 6 minutes increased from $240 \mathrm{~m}$ to $350 \mathrm{~m}(110 \mathrm{~m})$, even if the predicted $740 \mathrm{~m}$ calculated with the Enrigth 


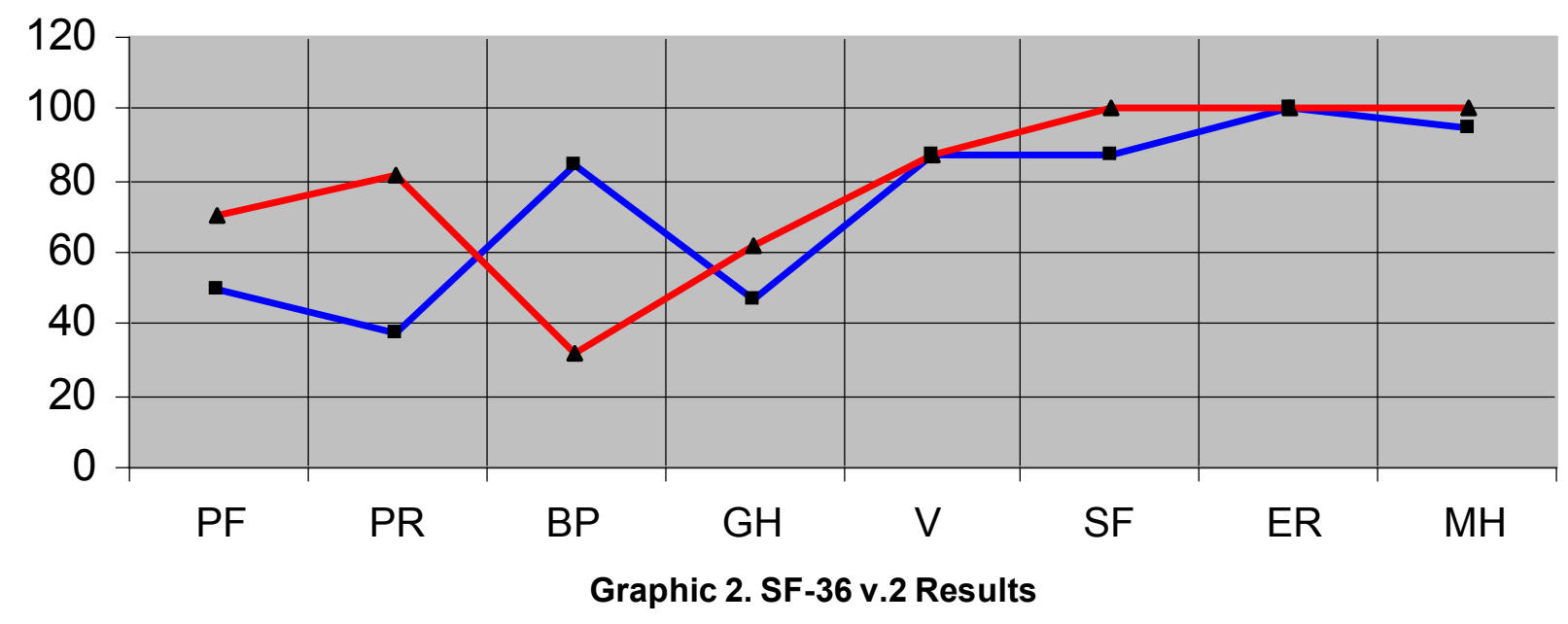

The blue line makes reference to the pre-test results. The red line makes reference to the values in the post-test. PF: Physical function; PR: Physical role; BP: Body pain; GH: General health V: Vitality; SF: Social functioning; ER: Role emotional; $\mathrm{MH}:$ Mental health

July $24^{\text {th }}, 2007$. Pulmonary Rehabilitation Program

formula were not reached. The heart rate and respiratory frequency decreased at the end of the rehabilitation $\operatorname{program}($ Graph 1). When determining the magnitude of the changes and characteristics of this patient after the pulmonary rehabilitation program, we found improvement in the perception of the dyspnea measured with the MRC scale from 4 to 1 (4: Very severe; 1 : mild) and with the Borg scale from 7 to 0 . The need for oxygen was reevaluated at the end of the rehabilitation program and showed improvement, as the patient was able to stay still without oxygen support and keep the $\mathrm{SpO}_{2}$ over $89 \%$. It was possible to decrease the $\mathrm{FIO}_{2}$ from 5 to 1 liter $/ \mathrm{m}$ during daily-life activities. The global muscle strength of upper and lower limbs increased from 3 to 4 according to Daniels' Scale, which goes from 0 to 5 (3: movement can beat the action to gravity, and 4: movement against gravity with partial resistance).

Pasipanoyda et al. ${ }^{5}$ validated the St. George qualityof-life questionnaire (SGRQ) in a population that was microbiologically cured from $\mathrm{Tb}$, and found a difference (mean of $13.5-\mathrm{U}$ ) in the SGRQ score between these patients and a control group (latent $\mathrm{Tb}$ ) with similar risk factors $(p<0.001)$. The total mean of the score for treated $\mathrm{Tb}$ patients was significantly higher than that of patients with latent $\mathrm{Tb}$ (23.5 vs. 10.3, respectively) $\mathrm{p}<0.001$. The investigators suggest that this difference demonstrates the deterioration after antituberculous treatment, which has great worldwide impact on health, and concluded that a microbiological cure for $\mathrm{Tb}$ is not enough to avoid loss of health ${ }^{5}$.

For this patient, quality of life was measured with the SF-36v2, and according to the physical dimensions (Physical Function, Physical Role, Body Pain, Vitality, and General Health) and the psychosocial dimensions (Social Function, Mental Health, and Emotional Role) that make up the questionnaire. Medium and high values were found at the end of the training program, generally indicating a good quality of life in these dimensions when compared to the scores obtained on the initial evaluation, as shown in Graph 2.

At the end of the rehabilitation program, the patient accomplished functionality in moving through flat areas and going up and down stairs. His participation in selfcare activities improved until he reached 100\% independence, and increased his participation in leisuretime activities. He is currently expecting to start training in information systems to complement his productive areas. His hypoacusia was treated with earpieces, which allowed him to improve his communication function.

In the psychological re-evaluation, the patient revealed a positive perception of himself, referring to his current state of health as «very good», with a score of 0 for both states on the HAD scale. A clear will to get better and keep on growing in his life, spiritually as well as professionally, was observed in the patient. 
The positive response to the pulmonary rehabilitation program in terms of functionality has encouraged the present authors to communicate the results obtained. Though said results cannot be applied to all the MDRTB community, they can be indicators when forming the basis of rehabilitation processes in these patients. For this MDR-TB patient, a 32-week period of pulmonary rehabilitation was sufficient to improve the distance covered in the 6MWT, improve the quality of daily-life activities, improve the quality of life, and reduce symptoms.

Education for the patient and family is considered an essential component in the attention of any chronic disease. This component, as well as the nutritional component, was not fully developed with this patient. This is why it is recommended to establish strategies that make the development of the educational component easier and ensure the evaluation and tracking of the nutritional state of patients in the rehabilitation program.

It is necessary to develop studies on these types of patients with other measures for evaluating results, such as the number of hospitalizations and the participation in daily-life activities, to confirm the results obtained. Though experience in this subject is limited, it is necessary not only to think about adapting the healing strategies for patients with MDR-TB, but to also think about the rehabilitation process integrating a group of actions aimed at helping patients to reach optimum functional, mental, and/or social levels in the areas in which they perform in their daily lives.

\section{REFERENCES}

1. Asociación Latinoamericana de Tórax (ALAT). Guías latinoamericanas de diagnóstico y tratamiento de la tuberculosis fármaco resistente. [cited 2007 Abr 7]. Available from: URL: http://www.alatorax.org/archivos/guias TBCfinales.pdf

2. Charles F, Ries AL, Bauldoff S, Carlin BW, Casaburi R, ZuWallack R, et al. Pulmonary rehabilitation: ACCP/AACVPR evidence-based clinical: Practice guidelines. Chest. 2007; 131: 4-42.

3. Hnizdo E, Singh T, Churchyard G. Chronic pulmonary function impairment caused by initial and recurrent pulmonary tuberculosis following treatment. Thorax. 2000; 55:32-8.

4. Ando M, Mori A, Esaki H, Shiraki T. The effect of pulmonary rehabilitation in patients with post-tuberculosis. Lung Disorder Chest. 2003; 123:1988-95.

5. Pasipanodya JG, Miller TL, Vecino M, Munguia G, Bae S, Drewyer G. Using the St. George Respiratory Questionnaire to ascertain health quality in persons with treated pulmonary tuberculosis. Chest. 2007; 132: 1591-8. 